\title{
THE IMPORTANCE OF MEMORIES IN THE TRANSMEDIA ERA
}

\section{Ariane Cristina Gervásio da Silva, Brazilian Association of Audiovisual Archives, Brazil}

\section{The Transmedia Phenomenon}

In 2003, Henry Jenkins coined the concept of transmedia. The early ideas on the topic came from discussions about the future of the entertainment industry, in particular, the games industry. Jenkins noted that the phenomenon was not new, but particularly in the 2000's the games narratives were expanding beyond games to other media. This trend was lucrative for the game industry-expanding an audience with new markets-and for audiences increasingly interested in complementary narratives of stories, such as detailed parallel plots or character's background stories:

Younger consumers have become information hunters and gatherers, taking pleasure in tracking down characters' backgrounds and plot points and making connections between different texts within the same franchise. And in addition, all evidence suggests that computers don't cancel out other media; instead, computer owners consume on average significantly more television, movies, CDs, and related media than the general population (Jenkins, 2003 p.I).

The prosumers (producers + consumers) contribute to the expansion of the narrative world when they comment, share, analyze, and end up creating layers of information. In the transmedia era, a product can be converted from original versions to new versions. Books can be turned into movies, or cartoons can generate comics or TV series, for example. Worth mentioning are franchises such as Indiana Jones, Star Wars - that became games, books, toysand the TV series Dawson's Creek and a lot of Marvel Comics that also had their narratives expanded. According to Scolari (2013), another important concept related to transmedia is storytelling, or, the way the story is told in different languages (verbal, iconic) and different media (cinema, comics, television, toys, games). In fact, the transmedia phenomenon depends on the potential of each media to build different narratives that incorporate audience and complementary information:

In the ideal form of transmedia storytelling, each medium does what it does best-so that a story might be introduced in a film, expanded through television, novels, and comics, and its world might be explored and experienced through game play. Each franchise entry needs to be self-contained enough to enable autonomous consumption. That is, you don't need to have seen the film to enjoy the game and vice-versa (Jenkins, 2003 p.2).

Transmedia storytelling attracts different audiences and creates different forms of loyalty. The idea is to offer audiences, eager for information, complex, sophisticated, complementary, and shareable content. 


\section{Social Media Storytelling and "|" Digital}

Transmedia narratives can be also applied to social media such as Facebook, Instagram, Pinterest, YouTube, WhatsApp, Snapchat, and Twitter. Each social media have their own features and challenges - characteristics, layout, usability, resources - that can provide users different ways to tell corporate and individual stories through text, audio, illustrations, or videos. To people and corporations, an online presence also means a museum of yourself (Shikida \& Moura, 2007, p.269). By 2017 , video content will represent $74 \%$ of all internet traffic and more than 300 hours of video are being uploaded to YouTube every minute. More than 250 billion photos have been uploaded to Facebook and over 95 million photos and videos are shared on Instagram every day. Tweets with images receive $150 \%$ more retweets than tweets without images.'

All this process is not purely the result of social media usage, but is defined by a group of factors and keywords widely discussed by Negroponte (1996), Jenkins (2015):

I. Digital - material convergence from atoms to bits;

2. Interaction - instantly share, comment, and react;

3. Mobile devices - portable and multimedia devices in your own pockets;

4. Co-creation - possibilities to complement narratives with other users;

5. Do it yourself - being an expert is not necessary to create content;

6. Big data and personal data - used to guide your online preferences;

7. Media channels - different media to tell stories;

8. Narrowing and niches - content created for a specific group or interest;

9. Digital presence - to be important, people and institutions have to be on the Internet.

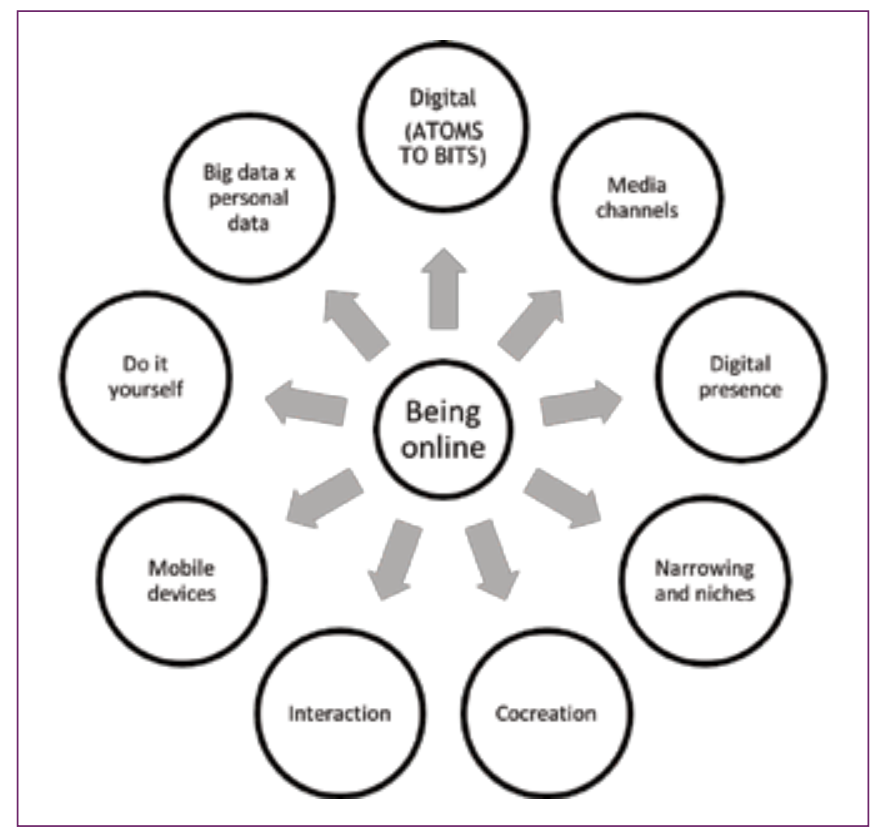

Figure I. Key factors related to being online in the Transmedia era.

I Data available at www.hubspot.com/marketing-statistics and www.socialpilot.co/blog/l 5 I-amazing-social-mediastatistics-know-2017/. 
The online phenomenon is recent and follows the expanding and popularization of Internet services. At first, users' participation and interactions were required the creation of an HTML personal site-often difficult to create for non-experts. At the beginning of 2000, these personal pages were replaced by blogs-supported largely by blog platforms, making it easier to use and create this content-where everybody who had internet access could share their experiences about themselves or some specific subject. Soon, the blogs became more complex and multimedia through photologs and videologs and the boom of instant messaging started, reflecting the idea of Web 2.0, which prioritizes person-to-person interaction. Today, social media are a mix of all the other stages of digital presence evolution where transmedia storytelling - creating a particular narrative-also defines the " $l$ " presence and "l" memories:

The evolution of social networks in this direction was predictable, since the tendency of Web 2.0 is to transform each person into an author, creating his own broadcast, becoming the center of a communication tool increasingly focused on the individual and his individualities (Shikida \& Moura, 2007, p.269).

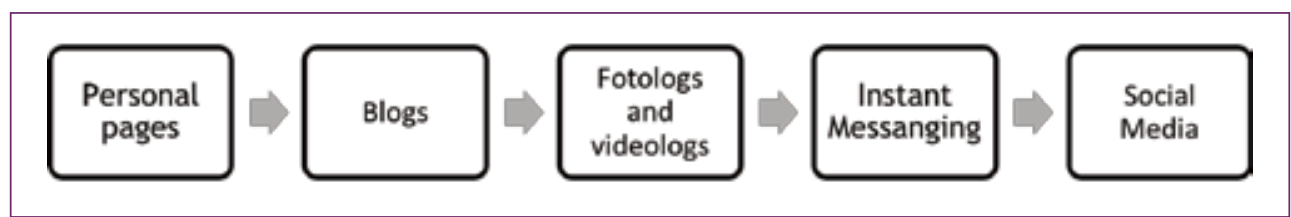

Figure 2. The evolution of digital presence.

Social media became a way to express individuality, providing to users the perfect environment for publishing texts, photos, videos, and information; and, therefore, became an important place to share memories. Previously, pictures and videos in albums and on video tapes were collective, collections of individuals joined with family and closer friends. Today, new memories are created using smartphones, delivered to the world on social media-commented on, reacted to, shared-and stored in personal accounts on social media platforms or digitally in a person's private storage.

The "l" presence and "l" memories are insured by a set of features that constitute social media. Social media platforms are often defined by timelines (chronology and linear layout), cataloging (content organized by hashtags, albums, categories), and editing (revise, hide, or delete information). Social media also provides tools (emojis, temperature, reactions and location), additional information (intersections with other apps and websites), and engagement (share and comment), all of which make online relationships similar to real-life interactions. Finally, multimedia and convergence, the former refers to the availability of different formats in the same place, and the latter guarantees that all different and complementary narratives can be experienced in the same place.

What people share in social media settings - text, picture, video, or other informationand the way they choose to share a story converge to define their I presence. The decision to remember and "archive" a story is an individual choice-l choice - mediated, shared, and stored through social media. 


\section{3. “|" Presence and Construction Of Selfie Memories}

One of the best examples of I presence is the selfie. The word comes from self-portrait, originally a drawing, sculpture, photograph, or painted portrait made by oneself about oneself. In this paper, the term selfie memory will be used to define information that people and institutions - users of social media - choose to share, react to, or comment about on social media. Oxford Dictionaries chose the word selfie as a World of the year 2013, based on the growth of pictures taken by users about themselves:

Early evidence for the term show a variant spelling with a -y ending, but the -ie form is vastly more common today and has become the accepted spelling of the word. It could be argued that the use of the-ie suffix helps to turn an essentially narcissistic enterprise into something rather more endearing. It also provides a tie-in with the word's seemingly Australian origins, as Australian English has something of a penchant for -ie words - barbie for barbecue, firie for firefighter, tinnie for a can of beer, to name just three (Oxford dictionaries, 20I3). ${ }^{2}$

Selfie memories are layers of information recorded on social media, the I presence built by a social media user as a creator of content and expressive actions in a digital setting. In the micro perspective of selfie memory, users have the power and autonomy to frame the steps of their own storytelling. First, the user chooses how to tell a story (by pictures, text or video), and then the ideal social media for telling the story, and then the user can interfere with the content using resources such as filters, in-platform editing, or icons.

The last step is for the user to decide between the three common types of publishing: live, temporary, or traditional.The live option is a real-time broadcast, very common on YouTube, Facebook and Instagram. More immediate, this type of publishing has its roots in the news, where the event broadcasted is assumed to be important and relevant with a social impact, e.g., journalistic coverage.

In the temporary publishing option, the content will be available for a short period of time. This option falls between immediate and long-term storage. It is widely used on Snapchat, Instagram, and Messenger (Facebook) according to the rules of their platforms. In most cases, stories are made available for 24 hours.

The third option, traditional storage, is a long-term publishing option available in some social media. This type of storage is not immediate or temporary, the content is stored and becomes a constant part of a user's storytelling online presence, defining their I presence, creating layers of information recorded in timelines, folders, and albums inside the social media platform or website.

2 Available on Oxford Dictionaries https.://en.oxforddictionaries.com/word-of-the-year/word-of-the-year-2013 


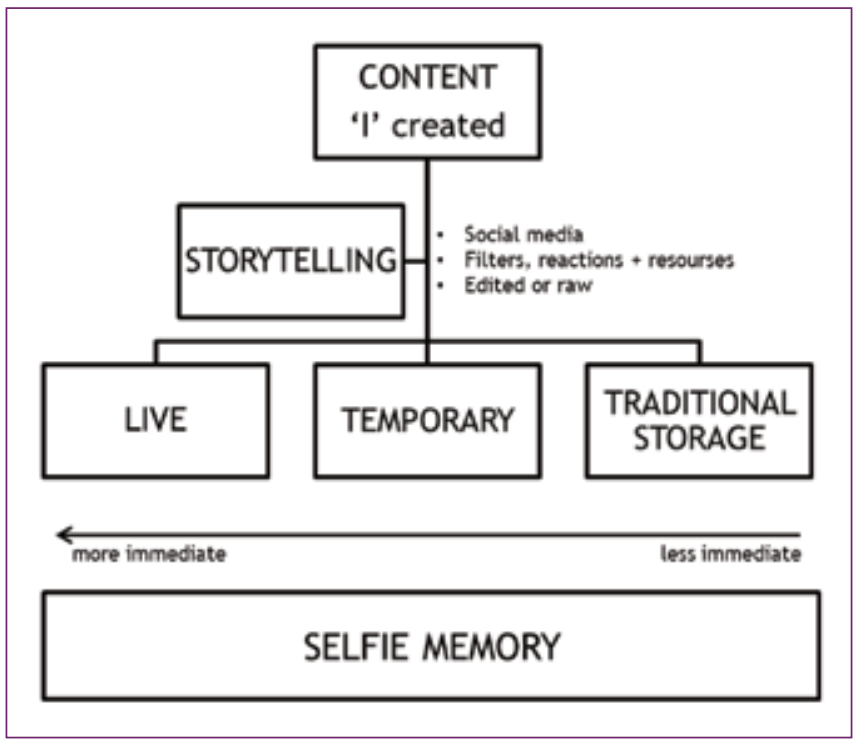

Figure 3. A content model, defining Selfie Memory as digital media object.

The macro perspective of selfie memory is framed by the triad of content creator (I), other creators (Others), and the particular social media platform (Social Media), in the context of two possible protocols: authorization and sovereignty, and authorization and interaction.

The first protocol - authorization and sovereignty - involves the relation between "I and Social Media" and "Others and Social Media." It is based on the platform-defined boundaries of sovereignty (algorithms used to connect users and the possibility of filter bubbles) and authorization (the terms of use and the experience-characteristics, layout, usability - chosen by the user). The second protocol involves the "I and Others" relationship based on authorization (allowing other users to be part of one's network, and privacy layers, including direct messages, public messages, and the ability to hide and edit information) and interaction (targeting, sharing, reacting, and engaging).

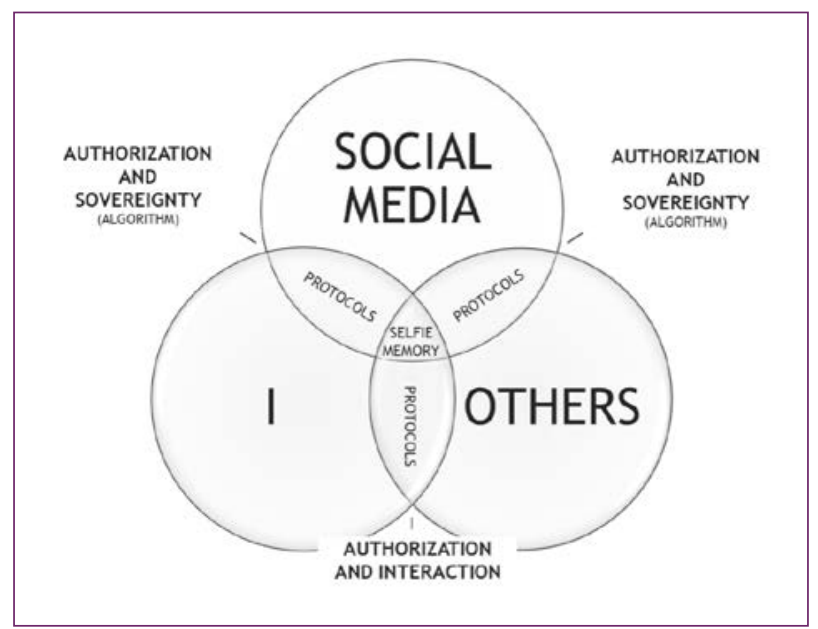

Figure 4. A macro perspective of Selfie Memory content. 
The macro perspective of selfie memories also suggests that the protocol of authorization and sovereignty guides the user of social media to non-selected memories based on the platform algorithm and the user's selected platform preferences. This idea can be illustrated, for example, when Facebook reminds the users what they wrote in the same date three years ago or requests to share how long the relationship between a user and a selected friend has existed on the platform. On the other hand, the protocol of authorization and interaction guides the user of social media to selected memories created by them and their network.

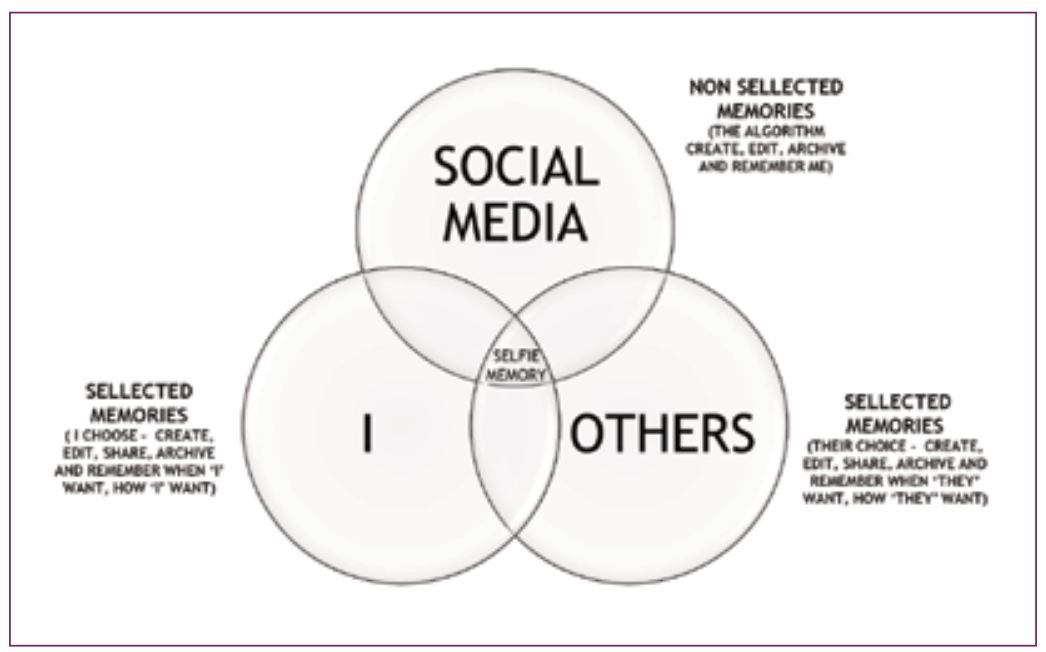

Figure 5. A macro perspective of Selfie Memory content, demonstrating selected vs. non-selected memories.

\section{Final Remarks}

Aside from presenting contemporary concepts, such as Transmedia and Storytelling, and their applications on social media, this paper aims to start a necessary discussion about personal and institutional memories-especially those that are embodied predominately as digital media content-from different perspectives. The first and more expressive goal is to illustrate the creators' perspective with their storytelling choices, including which social media was used and what content was published - text, image, audio, or video. The second focus is the makeup of a user's network and how users can interact - comment, share, react-with the content. The final perspective, the social media platforms themselves as institutions and companies, with their business interests and their platforms' algorithms and featured characteristics. The dynamic relationship between this triad provides us some idea of how, as archivists, to deal with memories created in social media, i.e., selfie memories.

Selfie memories also affect the experience of revisiting memories. Traditional methods for accessing memories (for example, documents, photos, videos in different media) that are experienced physically are now integrated with digital methods, more volatile but more accessible, as well. Today, self-published content online is a type of memory that is shared, commented on, and reacted to everyday by users, their networks, and the world. Today's fluid, convergent, and immediate digital atmosphere requires us to understand the I presence and selfie memories in the context of technological and human-created variables. 


\section{References}

Jenkins, H. (200I). Convergence? I Diverge. MIT Technology Review.

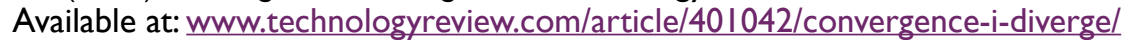
[Accessed 6 January 2018].

Jenkins, H. (2003). Transmedia Storytelling. MIT Technology Review.

Available at www.technologyreview.com/news/40/760/transmedia-storytelling [Accessed 6 January 2018].

Jenkins, H. (2006). Convergence Culture. São Paulo:Aleph.

Jenkins, H., Ito, M., \& Boyd, D. (2015). Participatory Culture in a Networked Era: A Conversation on Youth, Learning, Commerce, and Politics. Cambridge, UK: Polity.

Negroponte, N. (1996). Being Digital. New York:Vintage Books.

Scolari, C. (20I3). Narrativas Transmedia: Cuando todos los medios cuentan. Barcelona: Deusto

Scolari, C. (2009). Transmedia Storytelling: Implicit Consumers, Narrative Worlds, and Branding in Contemporary Media Production. International Journal of Communication. Available at: http://ijoc.org/index.php/ijoc/article/view/477/336 [Accessed 6 January 2018].

Shikida, A., Moura, M. (2007). Memória e redes sociais: informação e conhecimento em relatos orais. Encontro Nacional de Pesquisa em Ciência da Informação.

Available at: http://www.enancib.ppgci.ufba.br/artigos/GT3--132.pdf [Accessed 6 January 2018]. 